\title{
Type III Hyperlipoproteinemia and Spontaneous Atherosclerosis in Mice Resulting from Gene Replacement of Mouse Apoe with Human APOE`2
}

\author{
Patrick M. Sullivan, ${ }^{\star}$ Hafid Mezdour, ${ }^{\star}$ Steven H. Quarfordt, ${ }^{\ddagger}$ and Nobuyo Maeda* \\ *Department of Pathology and Laboratory Medicine, University of North Carolina, Chapel Hill, North Carolina 27599-7525; and \\ ${ }^{\ddagger}$ Department of Medicine, Durham Veterans Affairs Hospital and Duke University Medical Center, Durham, North Carolina 27705
}

\begin{abstract}
To study isoform-specific effects of apolipoprotein $\mathrm{E}$ (apoE) in vivo, we generated mice with a human $A P O E * 2$ allele in place of the mouse Apoe gene via targeted gene replacement in embryonic stem cells. Mice expressing human apoE2 (2/2) have virtually all the characteristics of type III hyperlipoproteinemia. Their plasma cholesterol and triglyceride levels are both twice to three times those in (normolipidemic) mice that are expressing human apoE3 (3/3) made in an identical manner. The $2 / 2$ mice are markedly defective in clearing $\beta$-migrating VLDL particles, and spontaneously develop atherosclerotic plaques, even on a regular diet. An atherogenic diet, high in fat and cholesterol, exacerbates development of atherosclerosis and xanthomas in the $2 / 2$ mice. Thus, comparisons between the $2 / 2$ and $3 / 3$ mice unequivocally demonstrate that a single amino acid difference (Arg158 Cys) in the apoE protein is sufficient to cause type III HLP and spontaneous atherosclerosis in mice. (J. Clin. Invest. 1998. 102:130-135.) Key words: apolipoprotein E • gene targeting $\bullet \beta-\mathrm{VLDL}$ clearance $\cdot$ clofibrate $\cdot$ planar xanthoma
\end{abstract}

\section{Introduction}

Type III hyperlipoproteinemia (HLP) ${ }^{1}$ is characterized by accumulation of chylomicron and VLDL remnants, collectively termed $\beta$-VLDL, which results in elevated plasma levels of total cholesterol (TC) and triglycerides (TG). Type III HLP occurs in 1 in 1,000-5,000 individuals, and if untreated will cause a large percentage of patients to develop xanthomas and premature atherosclerosis (1). The primary molecular cause of the disease is the presence of a dysfunctional form of apolipoprotein (apo) E, a critical ligand needed for plasma lipoprotein clearance. The majority of type III HLP individuals are homozygous for the apoE2 isoform, although in rare instances dominant apoE mutations are associated with the disease. ApoE2 differs from the most common isoform, apoE3, by only

Address correspondence to Dr. Nobuyo Maeda, Department of Pathology and Laboratory Medicine, The University of North Carolina at Chapel Hill, CB\# 7525, Chapel Hill, NC 27599-7525. Phone: 919966-6913; FAX: 919-966-8800; E-mail: nobuyo@med.unc.edu

Received for publication 29 December 1997 and accepted in revised form 22 April 1998.

1. Abbreviations used in this paper: apo, apolipoprotein; FPLC, fast protein liquid chromatography; HLP, hyperlipoproteinemia; IDL, intermediate density lipoprotein; TC, total cholesterol; TG, triglyceride.

The Journal of Clinical Investigation

Volume 102, Number 1, July 1998, 130-135

http://www.jci.org a single amino acid substitution, cysteine at position 158 in place of arginine. The binding affinity of apoE2 to the LDL receptor is $<1 \%$ of apoE3 in vitro (2). The majority of apoE2 homozygotes have below average plasma cholesterol levels, but $5-10 \%$ of homozygotes develop type III HLP. Thus, additional genetic, hormonal, or environmental factors are required to precipitate the disease (3).

In previous attempts to uncover the elusive precipitating factor(s) and to model type III HLP, transgenic animals have been generated by pronuclear injection of DNA expressing either one of the rare dominant forms of apoE $(4,5)$ or the apoE2 isoform (6-9). These animals have some of the characteristics of type III HLP, but rigorous comparisons to other transgenic mice expressing the common human apoE3 isoform are not possible because the transgenes were inserted into the genome in different copy numbers and in different chromosomal locations. For example, transgenic mice expressing low levels of human apoE2 are hypolipidemic, while those expressing high levels are hyperlipidemic (7). Additionally, the presence of endogenous mouse apoE protein in some cases complicates the interpretation of the phenotype.

We have previously reported the use of a gene replacement strategy to generate mice with a human $A P O E^{*} 3$ allele in place of the mouse Apoe gene, and have demonstrated that these mice express human apoE3 transcripts in a tissue-specific and physiological manner (10). Here we report generating mice that carry the human $A P O E^{*} 2$ allele in place of the mouse Apoe gene using the same procedure, and the use of these animals to study apoE isoform-specific effects in vivo.

\section{Methods}

Generation of homozygous human apoE2 mice. Replacement of the mouse Apoe gene with the human $A P O E^{*} 2$ allele was performed in mouse embryonic stem cells using the same strategy as previously described (10), except that the targeting construct contained exons 2-4 of $A P O E^{*} 2$ instead of $A P O E^{*} 3$. All the 2/2 and 3/3 mice used in this study were $129 / \mathrm{C} 57 \mathrm{BL} / 6 \mathrm{~F} 2$ generation hybrids. The $2 / 3$ heterozygotes were $\mathrm{F} 3$ generation mice derived from mating $2 / 2$ and $3 / 3$ animals. Animals were maintained on regular chow containing $4.5 \%$ fat and $0.022 \%$ cholesterol (Prolab Isopro Rat/Mouse/Hamster 3000[5P76]; Agway Inc., Syracuse, NY), or were fed an atherogenic diet that contains $15.8 \%$ (wt $/ \mathrm{wt})$ fat, $1.25 \%$ (wt/wt) cholesterol, and $0.5 \%$ (wt/wt) sodium cholate (TD 88051; Harlan Teklad, Madison, WI) or a western-style diet containing $21 \%$ fat and $0.2 \%$ cholesterol (TD 88137; Harlan Teklad). The animals were handled under protocols approved by the institutional animal care and use committees.

Plasma lipid and lipoprotein analysis. Animals fasted for $\sim 16 \mathrm{~h}$, and blood was collected from the retroorbital sinus. Within $1 \mathrm{~h}$ of blood collection, $1 \mu$ l of plasma was electrophoresed in precast $1 \%$ agarose gels (Ciba Corning Diagnostics Corp., Palo Alto, CA), and neutral lipids were visualized by Fat Red 7B staining (Sigma Chemical Co., St. Louis, MO). Plasma $(100 \mu \mathrm{l})$ from either individual or pooled samples was separated by gel filtration chromatography using a Superose 6 HR10/30 column (Pharmacia LKB Biotechnology, Inc., Piscataway, NJ). Fractions $(0.5 \mathrm{ml})$ were collected at a flow rate of 0.4 
$\mathrm{ml} / \mathrm{min}$. Cholesterol, free cholesterol, HDL-cholesterol, and TG were measured using enzymatic kits (Cholesterol CII, Free cholesterol C; Wako Bioproducts, Richmond, VA; Triglyceride [GPO-Triender]; Sigma Chemical Co.), and ApoE was measured using an ELISA with antibodies specific for human apoE as described (10). Isoelectric focusing of whole plasma was performed according to the method of Hackler et al. (11). SDS-PAGE and agarose gel immunoblot analyses were as described (10). Clofibrate (Atromid-S; Wyeth-Ayerst, New York, NY) was supplied in a normal chow diet $(0.5 \% \mathrm{wt} / \mathrm{wt})$ to 4 mice over $6 \mathrm{~d}$.

Clearance assay. ApoE $-/-$ mice were injected with ${ }^{14} \mathrm{C}$-labeled cholesterol. The $\beta$-VLDL fraction, which contained $72 \%$ of the tracer as cholesterol ester, was isolated $36 \mathrm{~h}$ later by centrifugation at a density of $1.010 \mathrm{~g} / \mathrm{ml}(10)$. Three mice of each genotype (apoE -/-, 2/2, and $3 / 3$ ) were fasted for $12 \mathrm{~h}$, injected with the labeled apoE-deficient $\beta$-VLDL, and serum samples were obtained at intervals up to $2 \mathrm{~h}$. The fractional catabolic rates and their variances were determined as described previously (12) using a two-compartment model. Male mice maintained on regular chow were used in this experiment.

Histological analysis. Segments of the proximal aorta and aortic sinus were embedded, sectioned, and stained as described (13). Morphometric measurements of the atherosclerotic lesion area for each animal were made from a section near the aortic valve.

Statistical analysis. The significance of differences between means was tested by using a two-tailed unpaired Student $t$ test or a nonparametric Mann-Whitney $U$ test.

\section{Results}

Plasma lipids in mice fed normal chow. Isoelectric focusing of whole plasma from mice homozygous for APOE*2 (2/2), heterozygous for $A P O E^{*} 2$ and $A p o E^{*} 3$ (2/3), and homozygous for $A P O E^{*} 3(3 / 3)$ shows that the mice are producing human apoE2 and apoE3 isoforms indistinguishable from those present in human plasma (Fig. $1 A$ ). However, the $2 / 2$ mice exhibit plasma lipid and lipoprotein profiles strikingly different from the profiles of $3 / 3$ mice. Thus, plasma TC and TG levels in the $2 / 2$ mice are two to three times higher than those in the 3/3 mice, which are themselves normolipidemic (Table I, $P<$ 0.0001). Animals of both sexes are equally affected, and plasma lipid levels are elevated at 2 mo of age and remain stable for over $1 \mathrm{yr}$. The HDL cholesterol levels in the $2 / 2$ and $3 / 3$ mice were not different. The plasma lipid levels in $2 / 3$ heterozygotes are normal (Table I), demonstrating that, as in humans, homozygosity of the apoE2 allele is needed to cause the hyperlipidemic phenotype. However, unlike humans in which apoE2 homozygosity is necessary but not sufficient to cause type III HLP, all the 2/2 mice, regardless of gender and age, develop hyperlipidemia, even on a low-fat and low-cholesterol diet. Thus, our findings suggest that the factor(s) responsible for precipitating type III HLP in humans homozygous for $A P O E^{*} 2$ are already present in mice.

Distribution of lipids and lipoproteins. Type III HLP has been described as broad-beta disease (14) because of the characteristic broad migration of $\beta$-VLDL on agarose gel electrophoresis. Both whole plasma and the $\mathrm{d}<1.006 \mathrm{~g} / \mathrm{ml}$ density fraction of plasma from $2 / 2$ mice show this broad $\beta$-migration pattern (Fig. $1 \mathrm{~B}$ ); in contrast, $3 / 3$ plasma shows virtually no lipid staining at the $\beta$-position. $\beta$-VLDL particles from the $2 / 2$ mice are highly enriched in cholesterol ester $(67 \%$ in $2 / 2$ compared with $<1 \%$ in $3 / 3$ mice), and have a VLDL cholesterolto-triglyceride ratio of 0.76 compared with 0.03 in the $3 / 3$ mice (a ratio $>0.3$ is diagnostic for type III HLP in humans [15]). Accumulation of $\beta$-VLDL in $2 / 2$ plasma is further illustrated
A

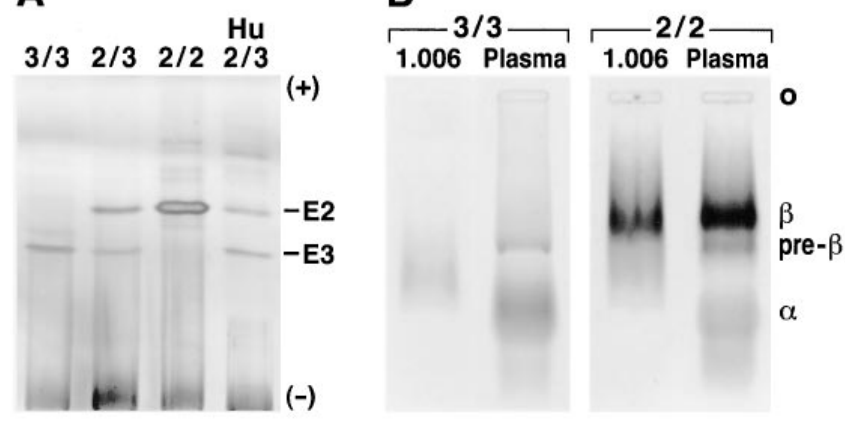

C

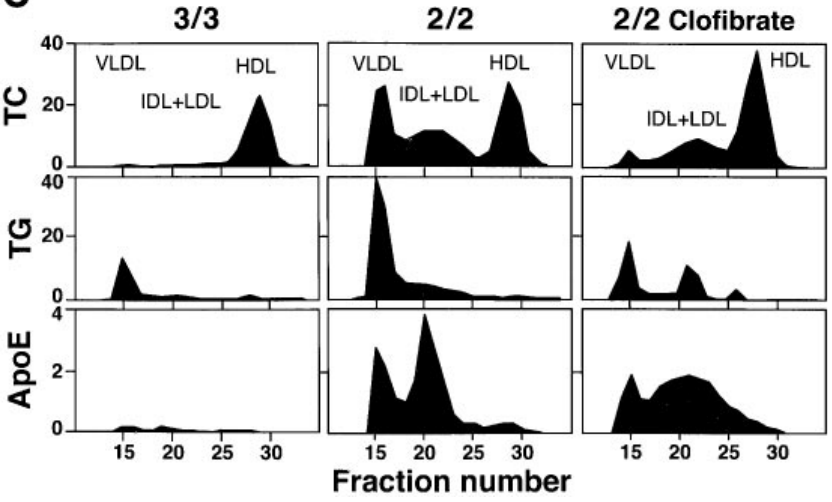

Figure 1. Type III HLP in the $2 / 2$ mice. (A) Detection of human apoE isoforms in plasma. Delipidated plasma samples from 2/2, 2/3, and $3 / 3$ mice were separated by isoelectric focusing, and the apoE proteins were visualized by silver staining after immunofixation with an antihuman apoE antibody (10). The positions of the human apoE isoforms-E2 and E3 - are indicated. A plasma sample from a human heterozygote APOE*2/APOE*3 (hu2/3) was used as a control. (B) $\beta$-VLDL migration in an agarose gel. Whole plasma (Plasma) or the $\mathrm{d}<1.006 \mathrm{~g} / \mathrm{ml}$ fraction (1.006) isolated by density ultracentrifugation was electrophoresed in a $1 \%$ agarose gel and stained with Fat Red 7B. The positions of the origin $(o), \alpha, \beta$, and pre- $\beta$ lipoproteins are indicated. $(C)$ Distribution of plasma lipoproteins and apoE. Pooled plasma $(100 \mu l)$ from ten $3 / 3$ and ten $2 / 2$ mice fed normal chow, and that from three $2 / 2$ mice fed chow containing $0.5 \%$ clofibrate (wt/wt) for $6 \mathrm{~d}$ were fractionated by FPLC (Pharmacia LKB Biotechnology, Inc.). Cholesterol $(T C)$, triglycerides $(T G)$, and ApoE content of each fraction $(0.5 \mathrm{ml})$ are expressed in $\mu \mathrm{g} /$ fraction.

by fast protein liquid chromatography (FPLC), which shows that $\sim 65 \%$ of the total cholesterol is in lipoproteins that elute in the VLDL-intermediate density lipoprotein (IDL) range (fractions 15-23, Fig. $1 \mathrm{C}$ ); in contrast, $>85 \%$ of the cholesterol in the $3 / 3$ mice is in the HDL range (fractions 27-31). The majority of TG in both groups of mice is in the VLDL fraction, although the TG levels in the $2 / 2$ mice are much higher than in the $3 / 3$ mice.

Plasma apoE2 levels in the $2 / 2$ mice were 16 -fold higher than apoE3 levels in the $3 / 3$ mice (Table I). ApoE2 was associated with lipoproteins in the VLDL-IDL range, and appeared as two distinct peaks (fractions 15 and 20) by FPLC analysis. SDS-PAGE of lipoproteins fractionated by sequential density ultracentrifugation of plasma from the $2 / 2$ mice agreed with the FPLC analysis in showing that the majority of apoE2 was 
Table I. Plasma Lipids and apoE Concentration

\begin{tabular}{|c|c|c|c|c|c|c|}
\hline Gender & Genotype & Diet & $\mathrm{TC}$ & TG & HDL-c & apoE \\
\hline & & & $m g / d l(n)$ & $m g / d l(n)$ & $m g / d l(n)$ & $m g / d l(n)$ \\
\hline \multirow[t]{5}{*}{ Females } & $2 / 2$ & ND & $238 \pm 48(16)$ & $184 \pm 46(15)$ & $50 \pm 19(15)$ & $21 \pm 5(12)$ \\
\hline & & HFC & $1297 \pm 311(9)$ & $40 \pm 16(9)$ & $10 \pm 5(9)$ & $43 \pm 10(9)$ \\
\hline & $2 / 3$ & ND & $81 \pm 10(5)$ & $54 \pm 16(5)$ & $43 \pm 6(3)$ & - \\
\hline & $3 / 3$ & ND & $75 \pm 15(11)$ & $48 \pm 13(10)$ & $52 \pm 15(7)$ & $1.3 \pm 0.5(10)$ \\
\hline & & HFC & $297 \pm 148(9)$ & $29 \pm 11(9)$ & $22 \pm 13(7)$ & $11 \pm 5(5)$ \\
\hline \multirow[t]{5}{*}{ Males } & $2 / 2$ & ND & $201 \pm 38(18)$ & $201 \pm 87(16)$ & $53 \pm 18(18)$ & $20 \pm 9(4)$ \\
\hline & & HFW & $595 \pm 58$ & $231 \pm 41(4)$ & $53 \pm 35(4)$ & $42 \pm 36(2)$ \\
\hline & $2 / 3$ & ND & $91 \pm 18(4)$ & $50 \pm 6(4)$ & $67 \pm 7(3)$ & - \\
\hline & $3 / 3$ & ND & $102 \pm 51(4)$ & $64 \pm 6(3)$ & $75 \pm 41(4)$ & $1.2 \pm 0.7(4)$ \\
\hline & & HFW & $172 \pm 66(4)$ & $64 \pm 17(4)$ & $91 \pm 37$ (4) & $4 \pm 2.5(4)$ \\
\hline
\end{tabular}

Data are means \pm SD in $\mathrm{mg} / \mathrm{dl}$ of mice receiving a normal chow diet (ND), a western type diet (HFW), or an atherogenic diet (HFC). Lipid levels of HFW-fed mice were measured $4 \mathrm{wk}$ after a 6-h fast. Mice on a ND and mice fed the HFC diet for 8 wk were measured after a 16-h fast. TC, total cholesterol; TG, tryglycerides.

in lipoprotein fractions of density range $1.006<\mathrm{d}<1.08 \mathrm{~g} / \mathrm{ml}$ (high plasma levels of apoE2 with the majority of apoE in remnant lipoprotein particles is another hallmark of type III HLP [16]). SDS-PAGE also revealed that both the ApoB100 and apoB48 amounts in 2/2 plasma were increased two- and eightfold, respectively, compared with the $3 / 3$ mice. ApoB 48 was increased equally in both VLDL and IDL-LDL fractions, while the increase in apoB100 was mainly in the VLDL fraction. The amount of apoB100 in the LDL fraction of $2 / 2$ mice was similar to that in the $3 / 3$ mice (data not shown).

Response to clofibrate treatment. Plasma lipid levels in type III HLP patients are usually responsive to lipid-lowering drugs such as fibric acid derivatives like clofibrate $(17,18)$. Treatment of the $2 / 2$ mice with clofibrate $(0.5 \%, \mathrm{wt} / \mathrm{wt}$ in chow) for $6 \mathrm{~d}$ altered their plasma lipid profiles dramatically in three out of four animals. The reason for the absence of change in one of the four animals is not currently known, but may be related to its genetic background since the tested animals were from the F2 generation. In the three animals that responded, mean plasma TG levels decreased from elevated $(188 \mathrm{mg} / \mathrm{dl})$ to normal levels $(61 \mathrm{mg} / \mathrm{dl}, P<0.001)$. A significant decrease in mean TC was also observed (from $255 \mathrm{mg} / \mathrm{dl}$ to $165 \mathrm{mg} / \mathrm{dl}, P<0.01$ ). FPLC analysis (Fig. $1 C$ ) showed a marked decrease in cholesterol and TG in the larger lipoproteins (VLDL-IDL range), while HDL cholesterol was increased. The lipoproteins in the HDL range were larger as judged by a shift in the HDL cholesterol peak. These alterations in plasma lipoprotein profiles after clofibrate treatment are again very similar to what has been observed in human patients treated with fibrates (19).

Delayed clearance of VLDL and spontaneous atherosclerosis. To test whether the accumulation of $\beta$-VLDL particles in the $2 / 2$ mice is the result of impaired clearance of the larger lipoproteins, we introduced ${ }^{14} \mathrm{C}$-radiolabeled remnant particles prepared from apoE $-1-$ mice into the circulation of $2 / 2$ mice. We found that $\sim 50 \%$ of the labeled particles remained in the circulation in the $2 / 2$ mice after $2 \mathrm{~h}$, as was also found when they were introduced into apoE $-/-$ mice. In contrast, virtually all the label was cleared from the circulation in the $3 / 3$ mice within $2 \mathrm{~h}$ (Fig. 2). The observed fractional catabolic rate
(FCR) was $0.007 / \mathrm{min}$ in the $2 / 2$ mice, $0.005 / \mathrm{min}$ in the apoE $-/-$ mice, and $0.02 / \mathrm{min}$ in the $3 / 3$ mice. These results show that the $2 / 2$ mice have a severe defect in clearing larger lipoproteins, in agreement with the observations by van Vlijmen et al. (6) that $A P O E^{*} 2$ transgenic mice lacking endogenous apoE are defective in clearing autologous ${ }^{125}$ I-labeled VLDL.

Any delay in the clearance of $\beta$-VLDL particles increases their residence time in blood, and would be expected to increase their atherogenicity. In confirmation of this expectation, we found atherosclerotic plaques in the proximal aorta of 10 -mo-old female $2 / 2$ mice maintained on regular chow. All seven $2 / 2$ females evaluated had plaques near the aortic root, with a cross-sectional area ranging from $2 \times 10^{4}$ to $2 \times 10^{5} \mu \mathrm{m}^{2}$ (average size, $9.4 \times 10^{4} \mu \mathrm{m}^{2}$ ). Fig. $3 \mathrm{~A}$ shows a representative section with plaques composed mainly of foam cells and some fibrous caps. In contrast, very much smaller plaques (average size, $1 \times 10^{3} \mu \mathrm{m}^{2}$ ), typically an accumulation of several foam cells, were found in only 4 of 11 female $3 / 3$ mice aged 10-12

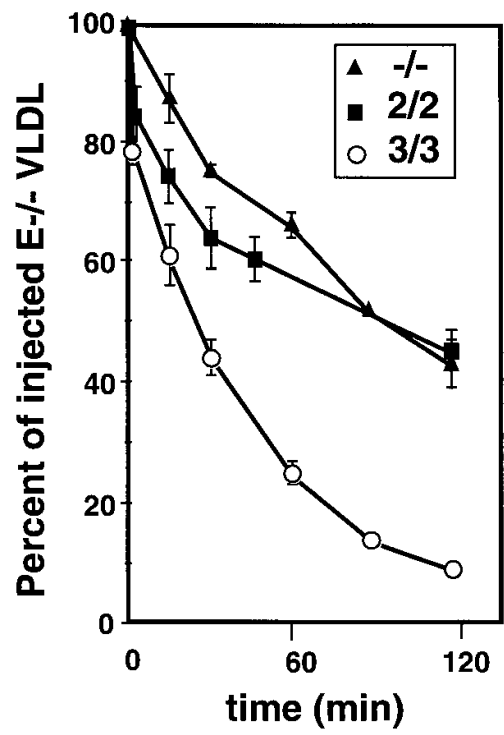

Figure 2. The plasma clearance of labeled apoE-deficient remnant particles. Three each of $2 / 2,-1-$, and $3 / 3$ mice were injected with radiolabeled apoE -/- remnant particles, and the label remaining in the plasma was measured for over $2 \mathrm{~h}$. Values (mean radioactivity remaining in the plasma \pm SEM) were significantly different among three groups except in $2 / 2$ and $-1-$ groups at $120 \mathrm{~min}$. 

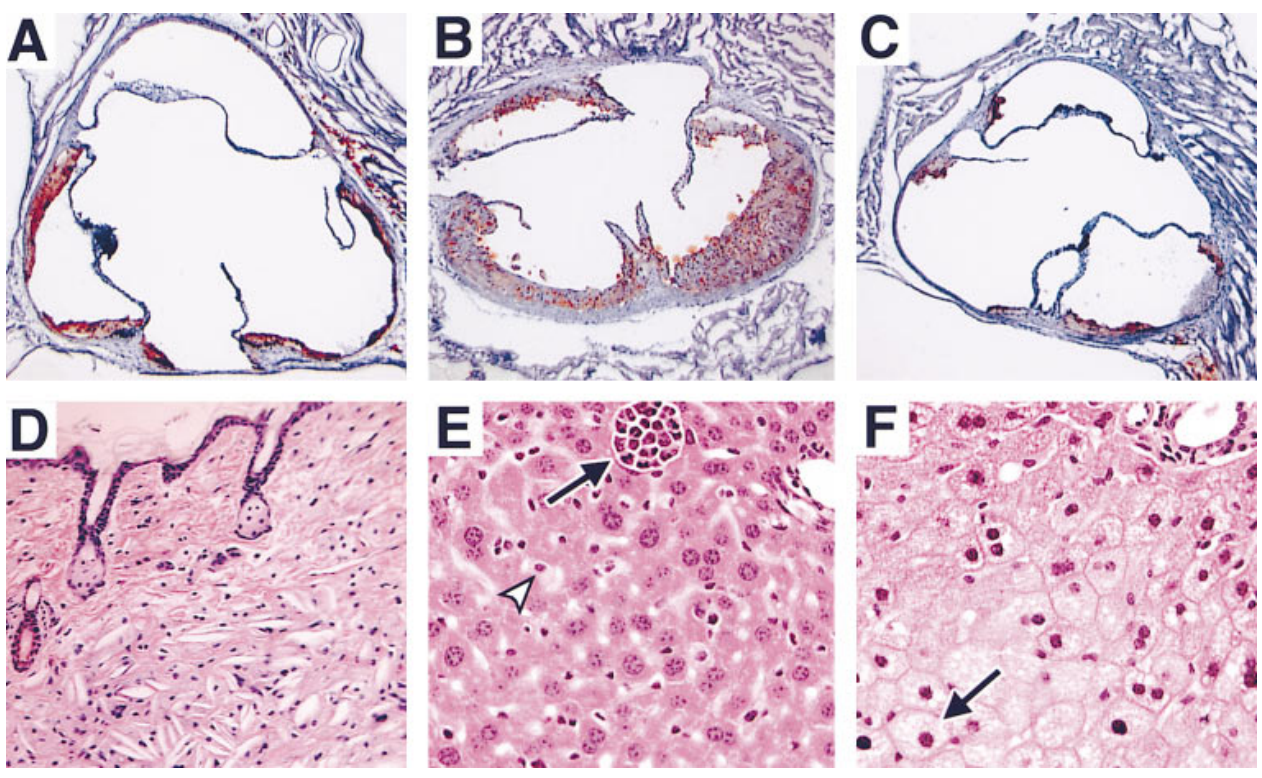

Figure 3. Histological analysis of atherosclerotic lesions, skin, and livers in $2 / 2,3 / 3$, or wild-type mice. $(A-C)$ Cross-sections of the aortic sinus area stained with Sudan IV B (Fisher Scientific Co., Pittsburgh, PA), and counterstained with hematoxylin $(100 \times)$. The micrographs are from $(A)$ a 10 -mo-old $2 / 2$ female mouse maintained on a normal chow diet (the atherosclerotic plaque consists mainly of foam cells); (B) a 5-mo-old 2/2 female mouse fed an atherogenic diet for 3 mo (the advanced stage lesion includes foam cells, necrotic cores, cholesterol clefts, and fibrous caps); (C) a 5-mo-old $3 / 3$ mouse fed the atherogenic diet for $3 \mathrm{mo}$ (the lesion consists mainly of foam cells); $(D)$ Severe xanthomatous lesion in the skin of a female $2 / 2$ mouse fed the atherogenic diet for $3 \mathrm{mo}$ (the lesion contains foam cells, cholesterol clefts, and neutrophils; hematoxylin and eosin, $400 \times) ;(E)$ liver section near a portal triad in a female $2 / 2$ mouse fed the atherogenic diet for 3 mo showing relatively normal hepatocytes, intrasinusoidal foam cells (white arrowhead), and focal extramedullary hematopoiesis (arrow; hematoxylin and eosin, 800×); and $(F)$ liver section near a portal triad in a female wild-type mouse fed the atherogenic diet for 3 mo, showing lipid-laden hepatocytes (arrow) together with anucleated and binucleated cells (hematoxylin and eosin, $800 \times$ ).

mo. No plaques were seen in wild-type $(+/+)$ mice of the same age.

Response to high-fat diets. When male $2 / 2$ mice were placed on a western-style diet containing $21 \%$ fat and $0.2 \%$ cholesterol, their plasma TC levels tripled $(P<0.001)$, accompanied by a slight but not statistically significant increase in TG, and no change in HDL cholesterol (Table I). On an atherogenic diet that contains $15.8 \%$ fat, $1.25 \%$ cholesterol, and $0.5 \%$ sodium cholate, female $2 / 2$ mice responded with a fivefold increase in plasma TC $(P<0.001)$, while their TG and HDL cholesterol levels were significantly reduced $(P<0.001$, Table I). The different responses of the TG and HDL levels between the two groups is most likely due to diets rather than to their sexes, although the mechanisms for these responses are not known. Control (3/3) mice responded to the respective diets similarly to the $2 / 2$ mice, but to lesser degrees.

Feeding the atherogenic diet for 3 mo enhanced plaque development in the female $2 / 2$ mice (mean size, $5.3 \times 10^{5} \mu \mathrm{m}^{2}$, $n=9)$; and the plaques were eight times larger than those found in the $3 / 3$ female mice $\left(6.4 \times 10^{4} \mu \mathrm{m}^{2}, n=6\right)$ on the same diet. Although the lesions in the $2 / 2$ mice consisted chiefly of foam cells, many also had fibrous caps, cholesterol clefts, and necrotic cores (Fig. $3 B$ ). In contrast, the lesions in the $3 / 3$ mice consisted solely of foam cells (Fig. $3 C$ ). Thus, a diet high in fat and cholesterol exacerbates the hyperlipidemia as well as development of atherosclerosis in the $2 / 2$ animals.

Another distinguishing characteristic of patients with type III HLP is the presence of planar and dermal xanthomas (20, 21). The atherogenic diet caused swelling of the carpi, paws, and periorbital area, and a dramatic deposition of lipid underneath the skin in the $2 / 2$ mice. Histological examination of the skin showed numerous foam cells, cholesterol clefts, and neutrophils in the hypodermis (Fig. $3 \mathrm{D}$ ). Lipid-laden macrophages were abundantly present in other tissues such as the fa- cial plane of skeletal muscle, submucosa of the esophagus, and the lymph nodes.

Feeding an atherogenic diet to wild-type mice long-term causes severe fatty changes in their livers (22). The livers of $2 / 2$ mice on the atherogenic diet, however, appeared relatively normal on gross examination, while the wild-type livers were enlarged and pale. Histologically, the $2 / 2$ livers had many lipidladen cells (presumably Kupffer cells) in the sinusoidal spaces surrounding hepatocytes with essentially normal appearance (Fig. $3 E$ ). In marked contrast, the hepatocytes in the wild-type livers were enlarged with microvesicular lipid deposits, and the numbers of anucleate and binucleate hepatocytes were increased (Fig. $3 F$ ). These changes and their differences between the $2 / 2$ and the $3 / 3$ mice suggest that the apoE2 is an ineffective ligand for removing lipoproteins via hepatocellular lipoprotein receptors, thereby protecting hepatocytes from fatty changes while accelerating lipoprotein uptake by a default pathway that likely involves macrophages and Kupffer cells.

\section{Discussion}

The data presented here clearly demonstrate that production at a physiological level of the human apoE2 isoform, but not of the apoE3 isoform, is sufficient to cause type III HLP and spontaneous atherosclerosis in mice. Virtually all the characteristics of the type III HLP seen in humans are present in the $2 / 2$ mice. These include a two- to threefold elevation in the plasma levels of TC and TG, a VLDL cholesterol-to-triglyceride ratio $>0.3$, broad migration of $\beta$-VLDL in agarose gel electrophoresis, and abnormally high plasma levels of apoE2 with the majority of the apoE2 being in remnant lipoprotein particles. Diets high in fat and cholesterol exacerbate the hyperlipoproteinemia found in the $2 / 2$ animals, in agreement 
with the inverse observation that changing to a low-fat, lowcholesterol diet alleviates the hyperlipidemia in most human type III HLP patients (1). Furthermore, reduction of plasma lipid levels and changes in lipoprotein profiles that occur in response to clofibrate treatment are similar in humans and in the $2 / 2$ mice.

The recapitulation in the $2 / 2$ mice of the phenotypes seen in human type III HLP makes these animals excellent models in which to investigate environmental and genetic factors that precipitate type III HLP and premature atherosclerosis in humans homozygous for the $A P O E^{*} 2$ allele. The mice may also help in determining the factor(s) that cause all $2 / 2$ mice to develop type III HLP, and may provide an insight into why only $5-10 \%$ of human $2 / 2$ individuals develop the disease. The differences between the apoE2 and apoE3 isoforms have a much larger impact in mice than in most humans, possibly because mice synthesize $\sim 70 \%$ of their liver-derived VLDL as apoB48 particles $(23,24)$. Mice consequently depend more on apoE for VLDL remnant clearance than do humans, in whom all the VLDL particles from the liver contain apoB100 and can be cleared via the LDL receptor independently of apoE.

Reduced plasma lipoprotein clearance due to hormonal, dietary, and genetic changes that lower LDL receptor expression is thought to be a factor that triggers the type III HLP phenotype in human patients (1). A similar reduction in clearance because of a defective interaction between the mouse LDL receptor and human apoE2 may account for the complete penetrance of type III HLP phenotype in our 2/2 mice. In contrast, interaction between human apoE3 and mouse receptors is sufficient for the $3 / 3$ mice to maintain normal plasma lipid levels when they are fed regular chow. Nevertheless, the 3/3 mice are more susceptible to diet-induced hyperlipidemia than are wild-type mice (10), suggesting that human apoE3 is still not as good of a ligand to mouse receptor(s) as mouse apoE protein. It is reasonable to expect that human apoE proteins would not be as good ligands to mouse receptor(s) as they are to human receptor(s), and further reduction of this interaction after the Arg-158 $\rightarrow$ Cys substitution in the apoE2 protein is the likely cause of the hyperlipidemia seen in the $2 / 2$ mice, even on the regular chow. Detailed studies on ligand/receptor interactions in these mice are therefore indicated. Spontaneous development of atherosclerosis in the $2 / 2$ mice fed regular chow, and its marked enhancement by feeding a high-fat and high-cholesterol diet have much in common with atherosclerosis that develops in mice that are unable to synthesize any apoE $(13,25,26)$, although the mean cross-sectional area of the atherosclerotic plaques in the $2 / 2$ mice is approximately half that seen in age-matched apoE $-/-$ mutants having a similar genetic background, and the $2 / 2$ plaques are less mature. There is a clear hierarchy in the degree of atherosclerosis among the four groups of animals that differ only at their Apoe locus. The severity decreases in the order $-1->2 / 2>$ $3 / 3>+1+$. The same order is observed when the circulation times of the atherogenic particles $(1 / \mathrm{FCR})$ are compared among these groups of animals. These observations consequently support the generally accepted view that any prolongation of the half-life of lipoproteins increases the likelihood that they will be modified (e.g., by oxidation) into atherogenic forms that are taken up by macrophages and smooth muscle cells $(27,28)$.

We conclude that the $2 / 2$ mice having the human apoE2 isoform expressed in a tissue-specific and physiological man- ner, and their comparison with the $3 / 3$ mice expressing the human apoE3 isoform, provide a powerful in vivo system for studying the structural and functional differences between these allelic forms of human apoE.

\section{Acknowledgments}

We thank Dr. A. Steinmetz for apoE typing using isoelectric focusing of mouse plasma, and Dr. V. Godfrey for reviewing histological preparations. We also thank M. Altenburg, S. Kim, K. Kluckman, C. Knouff, and A. Staton for technical assistance, and Drs. M. Hinsdale, O. Smithies, and L. Toth for discussion.

This work was supported by National Institutes of Health grant HL42630.

\section{References}

1. Maley, R.W., and S.C. Rall, Jr. 1995. Type III hyperlipoproteinemia (dysbetalipoproteinemia): The role of apolipoprotein $\mathrm{E}$ in normal and abnormal lipoprotein metabolism. In The Metabolic and Molecular Basis of Inherited Diseases. A.L. Beaudet, W.S. Sly, and D. Valle, editors. MacGraw-Hill, New York. 1953-1980.

2. Weisgraber K.H., T.L. Innerarity, and R.W. Mahley. 1982. Abnormal lipoprotein receptor-binding activity of the human $\mathrm{E}$ apoprotein due to cysteinearginine interchange at a single site. J. Biol. Chem. 257:2518-2521.

3. Utermann, G., M. Hees, and A. Steinmetz. 1977. Polymorphism of apolipoprotein $\mathrm{E}$ and occurrence of dysbetalipoproteinemia in man. Nature. 269: 604-607.

4. Fazio, S., Y.-L. Lee, Z.-S. Ji, and S.C. Rall, Jr. 1993. Type III hyperlipoproteinemic phenotype in transgenic mice expressing dysfunctional apolipoprotein E. J. Clin. Invest. 92:1497-1503.

5. van den Maagdenberg, A.M.J.M., M.H. Hofker, P.J.A. Krimpenfort, I. de Bruijn, B. van Vlijmen, H. van der Boom, L.M. Havekes, and R.R. Frants. 1993. Transgenic mice carrying the apolipoprotein E3-Leiden gene exhibit hyperlipoproteinemia. J. Biol. Chem. 268:10540-10545.

6. van Vlijmen, B.J.M., K.W. van Dijk, H.B. van’t Hof, P.J.J. van Gorp, A van der Zee, H. van der Boom, M.L. Breuer, M.H. Hofker, and L.M. Havekes. 1996. In the absence of endogenous mouse apolipoprotein $\mathrm{E}$, apolipoprotein E*2 (Arg158Cys) transgenic mice develop more severe hyperlipoproteinemia than apolipoprotein E*3-Leiden transgenic mice. J. Biol. Chem. 271:3059530602.

7. Huang, Y., S.W. Schwendner, S.C. Rall, Jr., and R.W. Mahley. 1996. Hypolipidemic and hyperlipidemic phenotypes in transgenic mice expressing human apolipoprotein E2. J. Biol. Chem. 271:29146-29151.

8. Huang, Y., S.W. Schwendner, S.C. Rall, DA. Sanan, and R.W. Mahley. 1997. Apolipoprotein E2 transgenic rabbits. Modulation of the type III hyperlipoproteinemic phenotype by estrogen and occurrence of spontaneous atherosclerosis. J. Biol. Chem. 272:22685-22694.

9. Huang, Y., S.C. Rall, Jr., and R.W. Mahley. 1997. Genetic factors precipitating type III hyperlipoproteinemia in hypolipidemic transgenic mice expressing human apolipoprotein E2. Arterioscler. Thromb. Vasc. Biol. 17:2817-2824.

10. Sullivan, P.M., H. Mezdour, Y. Aratani, C. Knouff, J. Najib, R.L. Reddick, S.H. Quarfordt, and N. Maeda. 1997. Targeted replacement of the mouse apolipoprotein E gene with the common human APOE3 allele enhances dietinduced hypercholesterolemia and atherosclerosis. J. Biol. Chem. 272:1797217980.

11. Hackler, R., J.R. Schafer, S. Motzny, S. Brand, T.O. Kleine, H. Kaffarnik, and A. Steinmetz. 1994. Rapid determination of apolipoprotein E phenotypes from whole plasma by automated isoelectric focusing using PhastSystem and immunofixation. J. Lipid Res. 35:153-158.

12. Quarfordt, S.H., B. Oswald, B. Landis, H.S. Xu, S.H. Zhang, and N. Maeda. 1995. In vivo cholesterol kinetics in apolipoprotein E-deficient and control mice. J. Lipid Res. 36:1227-1235.

13. Zhang, S.H., R.L. Reddick, J.A. Piedrahita, and N. Maeda. 1992. Spontaneous hypercholesterolemia and arterial lesions in mice lacking apolipoprotein E. Science. 258:468-471.

14. Fredrickson, D.S., R.I. Levy, and R.S. Lees. 1967. Fat transport in lipoproteins-an integrated approach to mechanisms and disorders. N. Engl. J. Med. 276:34-44.

15. Hazzard, W.R., and E.L. Bierman. 1975. Broad- $\beta$ disease versus endogenous hypertriglyceridemia: levels and lipid composition of chylomicrons and very low density lipoproteins during fat-free feeding and alimentary lipemia. Metabolism. 24:817-828.

16. Chappell, D.A. 1988. Pre-beta-very low density lipoproteins as precursors of beta-very low density lipoproteins. A model for the pathogenesis of familial dysbetalipoproteinemia (type III hyperlipoproteinemia). J. Clin. Invest. 82:628-639. 
17. Schaeffer, E.J., and R.I. Levy. 1985. Pathogenesis and management of lipoprotein disorders. N. Engl. J. Med. 312:1300-1310.

18. Brewer, H.B. Jr., L.A. Zech, R.E. Gregg, D. Schwartz, and E.J. Schaefer. 1983. NIH conference. Type III hyperlipoproteinemia: diagnosis, molecular defects, pathology, and treatment. Ann. Intern. Med. 98:623-640.

19. Hoogwerf, B.J., J.P. Bantle, K. Kuba, I.D. Frantz, Jr., and D.B. Hunninghake. 1984. Treatment of type III hyperlipoproteinemia with four different treatment regimens. Atherosclerosis. 51:251-259.

20. Polano, M.K. 1974. Xanthomatosis and hyperlipoproteinemia. A review. Dermatologica. 149:1-9.

21. Parker, F. 1985. Xanthomas and hyperlipidemias. J. Am. Acad. Dermatol. 13:1-30.

22. Nishina, P.M., J. Verstuyft, and B. Paigen. 1990. Synthetic low and high fat diets for the study of atherosclerosis in the mouse. J. Lipid Res. 31:859-869.

23. Greeve, J., I. Altkemper, J.H. Dieterich, H. Greten, and E. Windler. 1993. Apolipoprotein B mRNA editing in 12 different mammalian species: hepatic expression is reflected in low concentrations of apoB-containing plasma lipoproteins. J. Lipid Res. 34:1367-1383.
24. Higuchi, K., K. Kitagawa, K. Kogishi, and T. Takeda. 1992. Developmental and age-related changes in apolipoprotein B mRNA editing in mice. $J$. Lipid Res. 33:1753-1764.

25. Plump, A.S., D.J. Smith, T. Hayek, K. Aalto-Setala, A. Walsh, J.G. Verstuyft, E.M. Rubin, and J.L. Breslow. 1992. Severe hypercholesterolemia and atherosclerosis in apolipoprotein E-deficient mice created by homologous recombination in ES cells. Cell. 71:343-353.

26. Zhang, S.H., R.L. Reddick, B. Burkey, and N. Maeda. 1994. Dietinduced atherosclerosis in mice heterozygous and homozygous for apolipoprotein E gene disruption. J. Clin. Invest. 94:937-945.

27. Goldstein, J.L., Y.K. Ho, S.K. Basu, and M.S. Brown. 1979. Binding sites on macrophages that mediate uptake and degradation of acetylated low density lipoprotein, producing massive cholesterol deposition. Proc. Natl. Acad. Sci. USA. 76:333-337.

28. Henricksen, T., E.M. Mahoney, and D. Steinberg. 1981. Enhanced macrophage degradation of low density lipoprotein previously incubated with cultured endothelial cells: recognition by receptors for acetylated low density lipoproteins. Proc. Natl. Acad. Sci. USA. 78:6499-6503. 